\title{
Crack-Free Processing of Hot-Pressed Silicon Nitride Ceramics using Pulsed YAG Laser*
}

\author{
Noboru MORITA**, Takehiro WATANABE** \\ and Yoshitaro YOSHIDA**
}

\begin{abstract}
It is difficult to eliminate recast layers and cracks in laser-machining caramics. These defects significantly detract from the excellent properties of ceramics. This paper describes the feasibility of a crack-free processing method for hot-pressed silicon nitride $\left(\mathrm{Si}_{3} \mathrm{~N}_{4}\right)$ ceramics using a yttrium aluminum garnet (YAG) laser. The Q-switched YAG laser pulses controlled at below $500 \mathrm{~ns}$ in duration and $10 \mathrm{kHz}$ in repetition rate are effective for the purpose of crack-free machining of $\mathrm{Si}_{3} \mathrm{~N}_{4}$ ceramics because the thermal stress is most likely localized only in the laser-heated shallow area. The integrity of the crack-free surface is evaluated by the fracture strength and residual stress. The strength of laser-processed test pieces is reduced by 10 to $20 \%$ compared with diamond-ground ones because the high residual compression layer generated during grinding is removed.
\end{abstract}

Key Words : High-Energy-Rate Beam Machining, Drilling, Ceramics, Crack Propagation, Residual Stress

\section{Introduction}

Advanced fine ceramics have many excellent physical and chemical properties. However, their hardness and brittleness make them difficult to machine. The focused laser beam is one of the tools which can be used to machine fine ceramics ${ }^{(1) \sim(4)}$. However, the laser machining method has some dissdvantages such as the generation of recast layers ${ }^{(5)}$ and the development of thermal-stress-induced cracks $^{(6)}$. These defects decrease the fracture strength of ceramics, and also worsen other good characteristics ${ }^{(7)}$. This is probably the primary reason why laser applications for machining ceramics have been limited $^{(8),(9)}$.

This paper describes the feasibility of a crackfree processing method for hot-pressed silicon nitride $\left(\mathrm{Si}_{3} \mathrm{~N}_{4}\right)$ ceramics using an yttrium aluminum garnet (YAG) laser. The influences of the laser waveforms,

- Received 7 th September, 1990. Paper No 89-0231 A

- Department of Mechanical Engineering, Faculty of Engineering, Chiba University, 1-33, Yayoi-cho, Chiba 260, Japan such as pulse duration, peak output power and pulse repetetion frequency on the generation of cracks and recast layers during laser drilling are evaluated. The fracture strength and the residual stress are measured for the purpose of evaluating the crack-free surface.

\section{Influences of Laser Waveforms on the Genera- tion of Cracks and Recast Layers}

\subsection{Experimental procedure}

Two types of YAG laser oscillators, a pulsepumped YAG laser with pulse durations of $120 \mu \mathrm{s}$ to 7 $\mathrm{ms}$ and a continuous-pumped YAG laser, were used in the present experiments.

Moreover, in order to obtain the laser pulses with durations in the order of magnitude of $10 \mu \mathrm{s}$, we set up a $100 \mathrm{~mm}$-diameter aluminum disk with a slit, as illustrated in Fig. 1, and rotated it at 10000 revolutions per minute using a DC motor so that the pulsed YAG laser beam was partly chopped by the slit through which it passed. The chopped laser beam with durations of $20 \mu \mathrm{s}, 65 \mu \mathrm{s}$ and $110 \mu \mathrm{s}$ can be obtained by using disks with slit widths of $1 \mathrm{~mm}, 3 \mathrm{~mm}$ and $5 \mathrm{~mm}$, respectively.

In addition, the laser pulses with durations of 160 
ns to 700 ns were oscillated by switching the AO (acoustooptic)-modulators mounted on the continuous-pumped YAG laser. These short pulses generated by AO-modulator operation are generally called $\mathrm{Q}-$ switched pulses.

The pulsed laser waveforms which were obtained in the manner described above are shown in Fig. 2. Table 1 shows combinations of laser parameters examined in the experiment, such as pulse duration $(t)$, output energy per pulse $(E)$, the number of irradiated pulses $(N)$, and the peak output power $(P)$. The number of irradiated pulses was controlled so

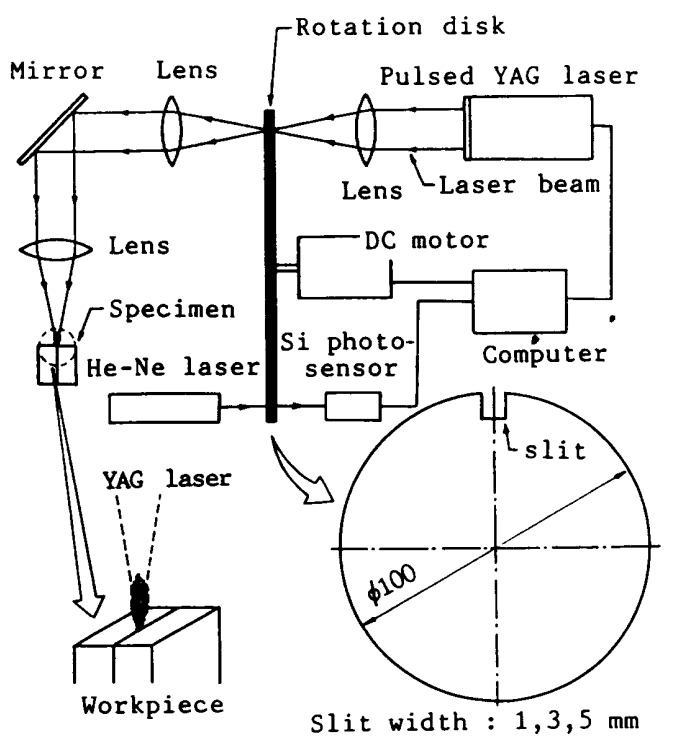

Fig. 1 Experimental equipment to obtain laser pulses with durations of the order of $10 \mu \mathrm{s}$

(a)Q-switching pulse

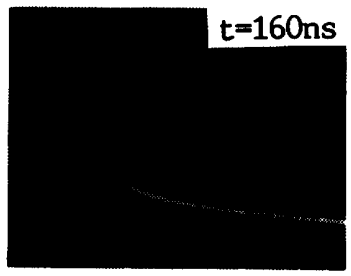

$0.2 \mu \mathrm{s} / \mathrm{div}$.

(c) Normal pulse
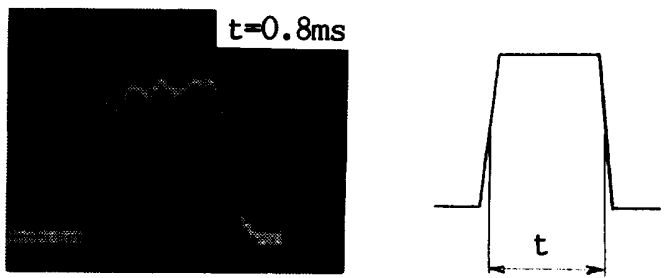

$0.2 \mathrm{~ms} / \mathrm{div}$

Fig. 2 Typical pulsed laser waveforms that the total output energy $E_{t}(=E \times N)$ was maintained constant at $24.4 \mathrm{~J}$, which was based on the energy of the longest pulse duration of $7 \mathrm{~ms}$. The peak output powers were made nearly fixed at $4 \mathrm{~kW}$, regardless of pulse durations, except that of the $\mathrm{Q}$ switched pulse.

The hot-pressed silicon nitride ceramics $\left(\mathrm{Si}_{3} \mathrm{~N}_{4}\right)$, which were sintered using $\mathrm{Y}_{2} \mathrm{O}_{3}$ and $\mathrm{Al}_{2} \mathrm{O}_{3}$ as sintering aids, were investigated. They were ground into $10 \times$ $15 \times 5 \mathrm{~mm}$ size by the resin-bond diamond wheel of \# 400 grains. The properties of $\mathrm{Si}_{3} \mathrm{~N}_{4}$ ceramics are indicated in Table $2 . \mathrm{Si}_{3} \mathrm{~N}_{4}$ ceramics are one of the ceramic materials which are very sensitive to constructive defects such as cracks and voids. In the observation of recast layers and cracks, a scanning electron microscope (SEM) and an X-ray microanalyzer (XMA) were used.

\subsection{Results}

$\mathrm{Si}_{3} \mathrm{~N}_{4}$ ceramics decompose into silicon vapor and nitrogen gas directly at about $2150 \mathrm{~K}$ under the condition of slow heating at atmospheric pressure. Rapid laser heating and vaporizing may very possibly produce the liquid silicon phase around the laserprocessed surface. Figure 3 shows the state of the crack development in the laser-drilled hole. The crack propagates from a recast layer (which looks white in the SEM photograph) into the matrix.

Figure 4 shows the characteristic $\mathrm{X}$-ray photographs of the recast layer. The recast layer contains richer silicon and yttrium elements than dose the

Table 1 Combinations of laser parameters examined in the experiment

\begin{tabular}{|c|c|c|c|c|c|c|c|c|}
\hline $\mathrm{t}$ & $160 \mathrm{~ns}$ & $500 \mathrm{~ns}$ & $20 \mu \mathrm{s}$ & $65 \mu \mathrm{s}$ & $110 \mu \mathrm{s}$ & $120 \mu \mathrm{s}$ & $800 \mu \mathrm{s}$ & $7 \mathrm{~ms}$ \\
\hline $\mathrm{E}$ & $10 \mathrm{~mJ}$ & $3.7 \mathrm{~mJ}$ & $75 \mathrm{~mJ}$ & $230 \mathrm{~mJ}$ & $380 \mathrm{~mJ}$ & $670 \mathrm{~mJ}$ & $3.2 \mathrm{~J}$ & $24.4 \mathrm{~J}$ \\
\hline $\mathrm{P}$ & 15.4 & 4.0 & 3.6 & 3.6 & 3.5 & 5.6 & 4.0 & 3.5 \\
\hline
\end{tabular}

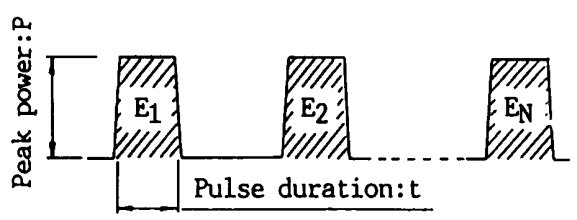

Energy: E

Table 2 Properties of $\mathrm{Si}_{3} \mathrm{~N}_{4}$ ceramics.

\begin{tabular}{lr}
\hline Specific heat (J/kg-K) & 712.3 \\
Density $\left(\mathrm{kg} / \mathrm{m}^{3}\right)$ & 3260 \\
Thermal conductivity (W/mK) & 29.3 \\
Poisson's ratio & 0.27 \\
Young's modulus (GPa) & 303.9 \\
Thermal expansion & 3.2 \\
$\quad$ coefficient $\left(\times 10^{-6} / \mathrm{K}\right)$ & \\
\hline
\end{tabular}


matrix. Figure 5 illustrates the silicon $K \beta \mathrm{X}$-ray emission spectrum observed in the recast layer. $\mathrm{X}$ - ray analyses identified the recast layer as $\mathrm{Si}$, not as $\mathrm{Si}_{3} \mathrm{~N}_{4}$

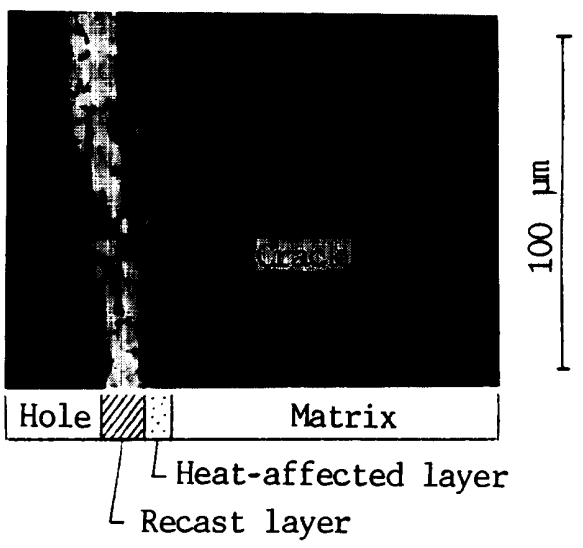

Fig. 3 State of the crack development in the laser-drilled hole

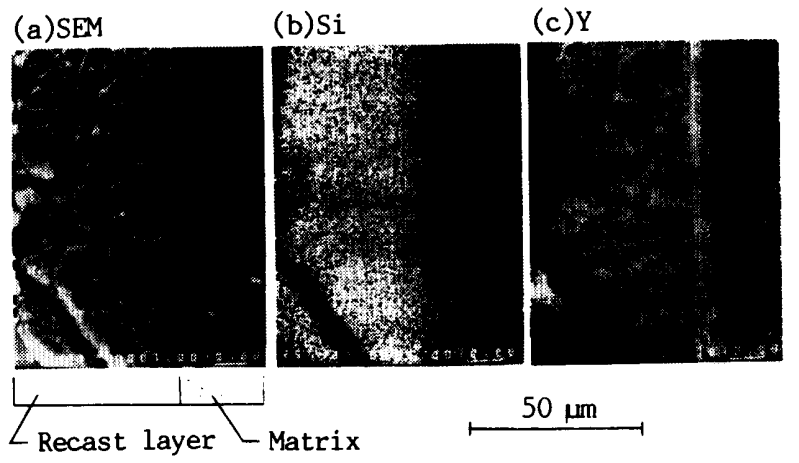

Fig. 4 Characteristic X-ray photographs of the recast layer

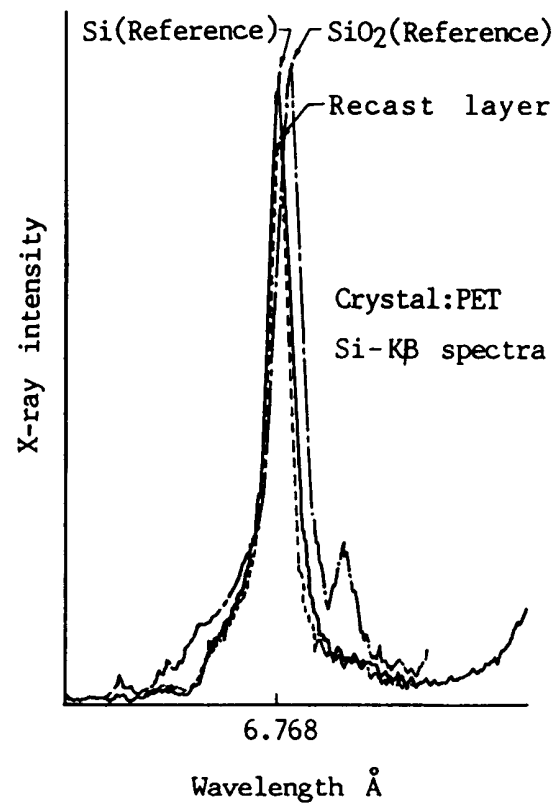

Fig. 5 Silicon $K \beta \mathrm{X}$-ray emission spectrum observed in the recast layer or $\mathrm{SiO}_{2}$. From these observations, we see that the recast layers are mainly composed of silicon.

We believe that the recast layer is formed because the silicon vapor generated by decomposition of $\mathrm{Si}_{3} \mathrm{~N}_{4}$ is saturated in the hole and condenses into liquid during laser heating.

Figure 6 shows the dependence of the crack length and the recast layer thickness on the peak output power. The increase in the peak output power causes the crack propagation and thick recast layer formation. It is necessary to maintain the peak output power as low as possible for crack-free machining ceramics.

Figure 7 illustrates the influences of the pulse duration on the crack length and the recast layer thickness. The crack length and the recast layer thick-

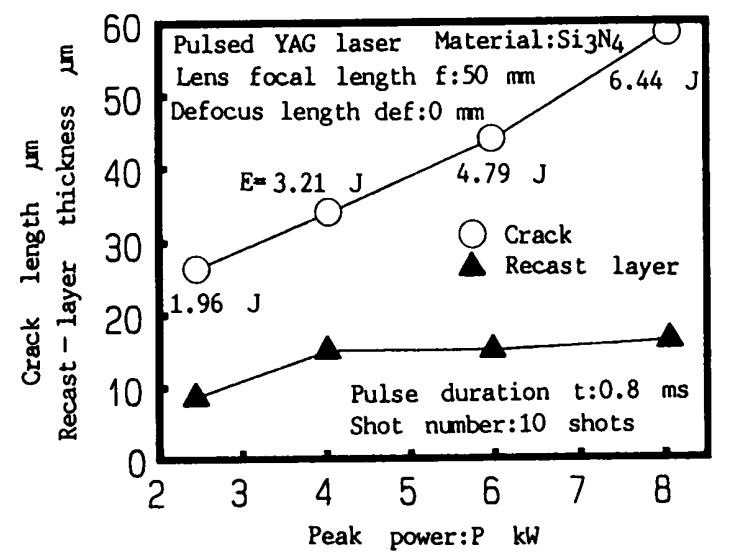

Fig. 6 Dependence of the crack length and the recast layer thickness on the peak output power

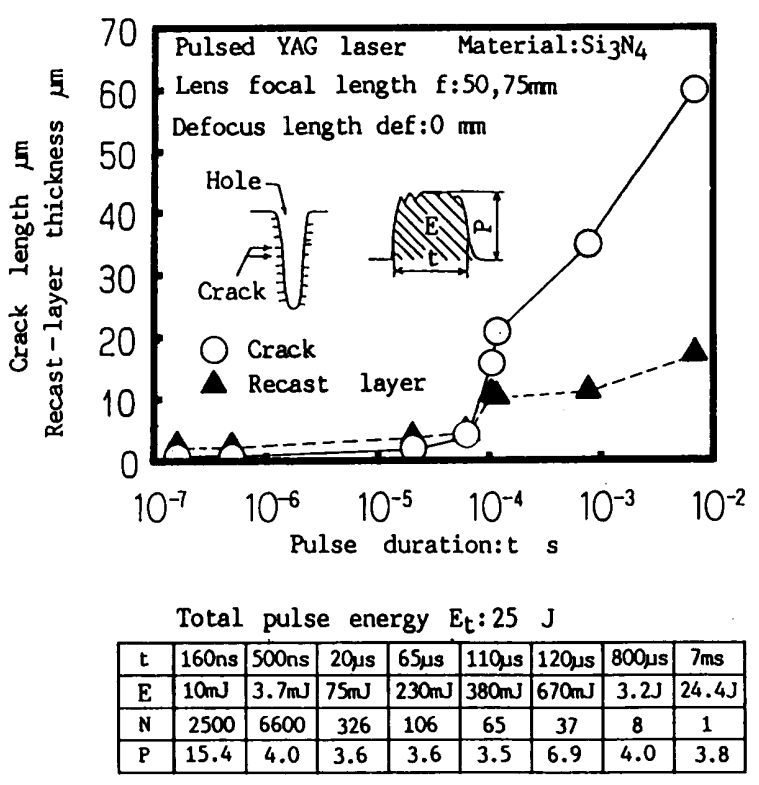

Fig. 7 Influences of the pulse duration on the crack length and the recast layer thickness 
ness are reduced with a decrease in the pulse duration. The crack length is smaller than the recast layer thickness when the pulse duration is less than $65 \mu \mathrm{s}$. This indicates that shallow cracks are developed within the recast layer without the growth of cracks into the matrix. In particular, no cracks were observed in the recast layer when $Q$-switched pulses with a duration shorter than $500 \mathrm{~ns}$ were used. This suggests that the thermal stress distribution induced by a short laser pulse is only localized in the laser-heated shallow area.

Figure 8 shows the dependence of the crack length and the recast layer thickness on the pulse repetition frequency. Repetition frequency higher than $10 \mathrm{kHz}$ thickens the recast layers and propagetes the cracks suddenly into the matrix. This result suggests that the short laser pulses with high repetition frequency establish a thermal stress distribution similar to that induced by a long laser pulse. The critical repetition frequency for crack-free processing shifted to the side of frequency lower than $10 \mathrm{kHz}$ when the higher peak output power was used.

Therefore, in order to achieve crack-free machining of $\mathrm{Si}_{3} \mathrm{~N}_{4}$ ceramics, it is necessary to process them using a laser beam pulsed for a duration of under 500 $\mathrm{ns}$ at a repetition frequency of less than $10 \mathrm{kHz}$. It appears that the crack development results from the thermal shock and the thermal expansion mismatch between the recast layer and matrix.

\section{Fracture Strength and Residual Stress of Crack-Free Surface}

\section{1 Experimental procedure}

Two techniques were used to evaluate the laserprocessed surface integrity. One technique involved the measurement of the fracture strength by the bending method, and another was residual surface stress measurement by an $\mathrm{X}$-ray diffraction tech-

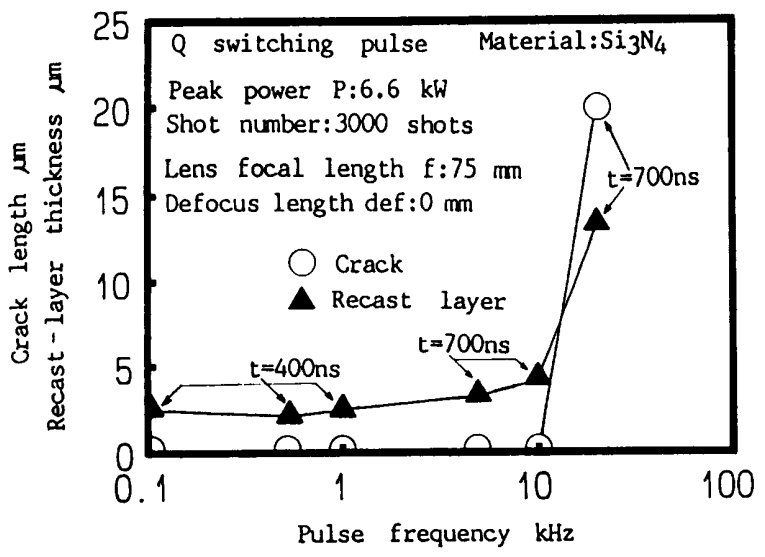

Fig. 8 Dependence of the crack length and the recast layer thickness on the pulse repetition frequency nique. The $\mathrm{X}$-ray method has been used previously to measure surface stresses in $\mathrm{Si}_{3} \mathrm{~N}_{4}$ ceramics ${ }^{(10)}$.

The standard test pieces for the three-point bending tests (in JIS R-1601) were made of the $\mathrm{Si}_{3} \mathrm{~N}_{4}$ ceramics given in Table 2 . They were finished into $3 \times$ $4 \times 40 \mathrm{~mm}$ size by a surface grinding process with a resin-bond diamond wheel of \# 600 grains. Subsequently, one side of the standard test pieces was finished by laser milling ${ }^{(11)}$. The removal thickness was controlled at $0.1 \mathrm{~mm}$ and $0.3 \mathrm{~mm}$ with the pulse repetition frequency of $320 \mathrm{~Hz}$ and $1 \mathrm{kHz}$, respectively. In this case, no cracks were observed in the very thin recast layer which was formed as a reaction product on the lasermilled surface. The bending strengths were analyzed by the Weibull statistics method. The residual stress in the ground and laser-processed surface was measured under the $\mathrm{X}$-ray diffraction conditions given in Table 3. In the present experiments, strain normal to the (411) lattice planes of $\beta-\mathrm{Si}_{3} \mathrm{~N}_{4}$ was measured using $\mathrm{Cr}-\mathrm{K} \alpha$ radiation. Residual stresses were compared with fracture strengths.

\subsection{Results}

Figure 9 shows the Weibull plots of fracture strengths with removal depth by laser milling. Table 4 shows the average strength and Weibull modulus. The

Table $3 \mathrm{X}$-ray diffraction conditions for residual surface stress measurement

\begin{tabular}{l|l}
\hline \multicolumn{2}{c}{ X-ray diffraction conditions } \\
\hline \hline X-ray diffraction method & Parallel beam method \\
Characteristic X-ray & $\mathrm{Cr} \alpha$ spectrum \\
Diffraction plane & $\beta-\mathrm{Si}_{3} \mathrm{~N}_{4}(411)$ \\
Diffraction angle (deg) & 125.58 \\
Filter & Vanadium foil \\
X-ray-irradiated area ( $\left.\mathrm{mm}^{2}\right)$ & $15 \times(2 \sim 3)$ \\
Tube voltage (kV) & 50 \\
Tube current (mA) & 40 \\
Divergent angle (deg) & 0.5 \\
Scanning speed (deg/min) & 0.45 \\
\hline
\end{tabular}

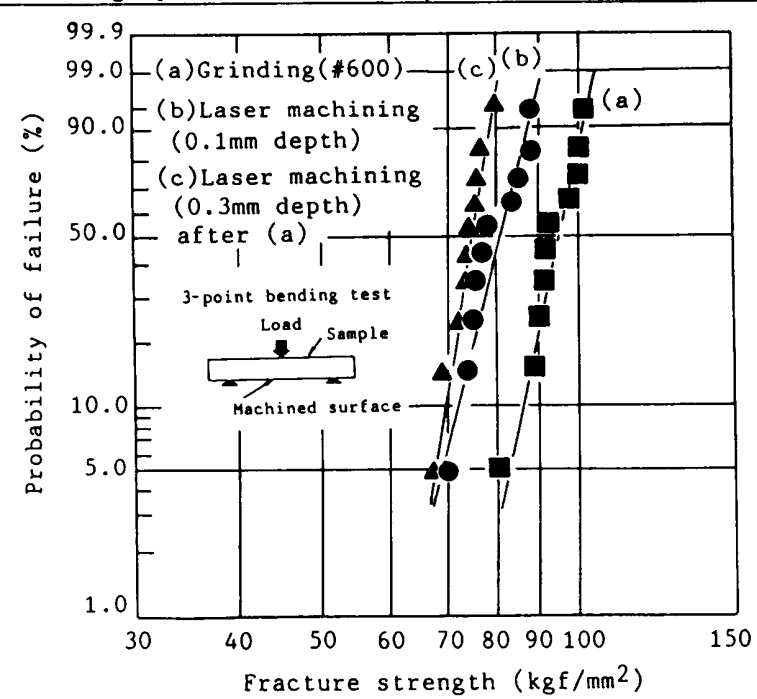

Fig. 9 Weibull plots of fracture strengths with removal depth by laser milling 
Table 4 Average strength and Weibull modulus with removal depth by laser milling

\begin{tabular}{l|cc}
\hline Machining method & $\begin{array}{c}\text { Average fracture } \\
\text { strength( }\left(\mathrm{kgf}_{\mathrm{fmm}}{ }^{2}\right)\end{array}$ & Weibull modulus \\
\hline (A) Grinding ( $\$ 600)$ & 93.9 & 18.7 \\
(B) Laser machining (0.1mm & 82.6 & 17.2 \\
$\begin{array}{c}\text { depth) after (A) } \\
\text { (C) Laser machining (0.3mm } \\
\text { depth) after (A) }\end{array}$ & 74.1 & 24.8 \\
\hline
\end{tabular}

average strengths of $0.1-\mathrm{mm}$ - and $0.3-\mathrm{mm}$-removed testpieces are about $88 \%$ and $79 \%$ that of the ground ones $\left(94 \mathrm{kgf} / \mathrm{mm}^{2}\right.$ ), respectively.

The strength reduction of 10 to $20 \%$ seems to be due to the very thin recast layer and residual surface stress. The variation of strength with removal of recast layers by 5 to $10 \mu \mathrm{m}$ lapping, which was about $2 \mathrm{kgf} / \mathrm{mm}^{2}$, was very small. The strength of lapped test pieces did not recover to the previous level ${ }^{(7)}$. This suggests that the fracture strength difference between laser-processed and ground test pieces is caused by the residual surface stress generated in the ceramic materials.

Results of X-ray residual stress determination are shown in Table 5. Residual compression stresses are generated in every test piece independently of the machining processes. The stress in diamond-ground $\mathrm{Si}_{3} \mathrm{~N}_{4}$ is nearly $10 \mathrm{kgf} / \mathrm{mm}^{2}$. This magnitude is 4 to 8 times that of laser-milled ones. This shows that the higher residual compression layer generated during grinding is removed by laser milling. For that reason, the average strength of laser-milled test pieces seems to be reduced.

It is well known that residual compression established by diamond grinding improves the mechanical properties and surface integrity such as fracture strength. In laser processing, however, we cannot obtain this improvement effect.

It has been shown that the average strength of test pieces processed with a $\mathrm{CO}_{2}$ laser and a normal pulsed YAG laser is 31 to $42 \%$ reduced compared to that of diamond-ground specimens ${ }^{(5)}$. Considering the factors described above, we conclude that the crackfree processing technique using the $\mathrm{Q}$-switched YAG laser, which has well-controlled pulse duration and repetition frequency, has great industrial possibilities.

\section{Conclusions}

We have pursued the possibility of the realization of crack-free processing of hot-pressed silicon nitride ceramics using an yttrium aluminum garnet (YAG) laser. It was found that the $\mathrm{Q}$-switched pulse $\mathrm{YAG}$
Table 5 Results of X-ray residual stress determination

\begin{tabular}{l|c}
\hline Measured surface & Residual stress $\left(\mathrm{kgf} / \mathrm{mm}^{2}\right)$ \\
\hline (A) Ground $(\$ 00)$ laser & $-9.82 \pm 1.14$ \\
(B) Ground $(\$ 400) \&$ lachined $(0.1 \mathrm{~mm}$ depth) & $-2.34 \pm 0.98$ \\
machind $(\$ 400) \&$ laser & $-1.19 \pm 0.98$ \\
(C) Ground & \\
machined $(0.3 \mathrm{~mm}$ depth) & \\
\hline
\end{tabular}

laser is effective for the purpose of crack-free machining of $\mathrm{Si}_{3} \mathrm{~N}_{4}$ ceramics if the pulse duration and repetition frequency are suitably controlled. The reason why the average strength of laser-processed test pieces is reduced by 10 to $20 \%$ compared with diamond-ground ones is that higher residual compression layer generated during grinding is removed by the laser process.

We conclude that this crack-free processing technique using the $\mathrm{Q}$-switched YAG laser has possibilities of further development.

\section{References}

(1) Chryssolouris, G., Bredt, J. and Kordas, S., The Winter Annual Meeting of ASME,PED-Vol. 17 (1985),p.9.

(2) Chryssolouris, G. and Bredt, J., Proceeding of International Symposium on Machining of Advanced Ceramic Material(1987), p. 1.

( 3 ) Chryssolouris,G. and Bredt, J., Interceram, Vol.37. No. 2(1988), p. 43.

(4) Wallace, R. J., Bass, M. and Copley, S. M., J. Appl. Phys., Vol. 59, No. 10(1986), p. 3555.

( 5 ) Wallace,R.J. and Copley,S.M.,Advanced Ceramic Materials, Vol. 1, No. 3(1986), p. 277.

(6) Paek, U. C. and Gabliano, F. P., IEEE Journal of Quantum Electronics, Vol.QE-8, No.2(1972) p.112.

(7) Sakamoto, H., Morita, N., Watanabe, T. and Yoshida Y., Proceedings of the First International Conference on New Manufacturing Technology Chiba (1990),p. 571.

(8) Morita, N., Watanabe, T. and Yoshida Y., Trans. Jpn. Soc. Mech. Eng., (in Japanese),Vol. 56, No.522-C(1990), p. 498.

( 9 ) Morita, N., Ishida, S., Fujimori, Y. and Ishikawa, K.,Pulsed Laser Processing of Ceramics in Water, Applied Physics Letter, Vol. 52, No. 23(1988), p. 1965.

(10) Walls, D. J., Evans, A. G., Marshall, D. B. and James, M. R., J. Am. Ceram. Soc., Vol. 69, No. 1(1986), p. 44.

(11) Morita, N., Sakamoto, H., Watanabe, T. and Yoshida Y., The Winter Annual Meeting of ASME, MD-Vol. 16(1989), p. 9. 